\title{
The role of endoscopic therapy in obesity management: intragastric balloons and aspiration therapy
}

This article was published in the following Dove Press journal: Diabetes, Metabolic Syndrome and Obesity:Targets and Therapy 6 July 2017

Number of times this article has been viewed

\author{
Nitin Kumar' \\ Shelby Sullivan ${ }^{2}$ \\ Christopher C Thompson ${ }^{3}$ \\ 'Bariatric Endoscopy Institute, \\ Addison, IL, ${ }^{2}$ Gastroenterology \\ Bariatric and Metabolic Program, \\ University of Colorado School \\ of Medicine, Denver, CO, \\ ${ }^{3}$ Gastroenterology and Therapeutic \\ Endoscopy, Brigham and Women's \\ Hospital, Harvard Medical School, \\ Boston, MA, USA
}

\begin{abstract}
Weight management is increasingly incorporating endoscopic bariatric therapy (EBT). As the global burden of obesity and its comorbidities has increased, it is evident that novel therapeutic approaches will be necessary to address the obesity epidemic. EBTs offer greater efficacy than diet and lifestyle modification and lower invasiveness than bariatric surgery. The US Food and Drug Administration has approved two intragastric balloons and aspiration therapy for the treatment of obesity: Apollo Orbera is indicated for the treatment of Class I and Class II obesity, Re Shape Integrated Dual Balloon system is indicated for the same range with a comorbidity, and Aspire Bariatrics AspireAssist is approved for patients with a body mass index of 35-55 $\mathrm{kg} / \mathrm{m}^{2}$. These devices have proven safe and effective in clinical trials and are gaining commercial acceptance in the USA; the Orbera has been used extensively outside the USA for over 20 years. These devices will need to be delivered in the context of a multidisciplinary weight loss program, integrating comprehensive care of obesity. Patient selection is important, and ensuring appropriate patient expectations and understanding of alternatives such as pharmacologic therapy and surgery is essential. With several EBTs on the horizon, patients with obesity will have an even broader array of safe and effective options for weight management in the future.
\end{abstract}

Keywords: intragastric balloon, Orbera, ReShape, AspireAssist, aspiration therapy, weight loss

\section{Introduction}

Obesity is a chronic medical disease affecting 81 million Americans, which constitutes over one-third of the adult population. ${ }^{1-3}$ Obesity-related diseases, including type 2 diabetes, hypertension, and obstructive sleep apnea, add to the burden on patients and the health care system. Several therapeutic options are available, although higher efficacy is correlated with higher invasiveness. Dietary and lifestyle modifications are unlikely to maintain significant long-term weight loss in the majority of patients. ${ }^{4}$ Bariatric surgery, which was performed in 47 per 100,000 adults in 2012, is the most successful treatment for individual patients, but has had limited effect on obesity at the population level due to its less utilization. ${ }^{5}$ There are multiple reasons for the low number of people opting for bariatric surgery, including invasiveness, cost, risk, food limitations, and access.

Endoscopic bariatric therapies (EBTs) fill the invasiveness and efficacy gaps in currently available options for the treatment of obesity. Three EBTs have been approved by the US Food and Drug Administration: the Orbera intragastric balloon, the ReShape Integrated Dual Balloon (IDB) system, and the Aspire Bariatrics AspireAssist. Although the devices are endoscopically placed, these therapies include a diet and lifestyle component that must be delivered concurrently. The delivery of EBT should
Correspondence: Nitin Kumar Gastroenterology and Weight Management, Bariatric Endoscopy Institute, I450 West Lake Street, Suite I0I, Addison, IL 60I0I, USA $\mathrm{Tel}+\mathrm{I} 6303879362$ Email nkumar@obesityendoscopy.org 
integrate a team of specialists with expertise in diet and lifestyle management, exercise, and behavioral modification. ${ }^{6}$

Patient selection is a key factor in achieving a successful outcome after EBT. Before EBT is delivered, eating disorders should be ruled out, or treated if found. A commitment should be made to a long-term weight management plan and to removal of the device. Medical diseases that can cause weight gain, such as hypothyroidism should be ruled out or treated. An assessment for contraindications to a specific EBT, such as hiatal hernia or prior gastric surgery with certain EBT, should be performed. This may require clinical assessment or endoscopy.

Delivery of EBT requires specialized preparation. The facility will should have examination tables, chairs, gowns, scales, and doorways capable of accommodating the size and weight levels of patients undergoing EBT, and also patients with higher classes of obesity who may seek EBT. Management of adverse events after EBT may require specialized services, such as in-office infusion to address dehydration associated with protracted nausea. Staff sensitivity training will ensure that patients with obesity feel welcome.

\section{Endoscopic therapy of obesity}

The intragastric balloon is a space-occupying device that takes up gastric volume. There are multiple proposed mechanisms of action, including delayed gastric emptying and hormonal changes. Contraindications to intragastric balloon placement include a history of gastrointestinal surgery, clotting or bleeding disorders, pregnancy, and large hiatus hernia. Once the balloon is removed at 6 months after insertion, the diet and lifestyle program should continue for another 6 months. Aspiration therapy entails placement of a large-bore percutaneous gastrostomy tube, with partial aspiration of meals after ingestion. When choosing between therapies, it is helpful to determine body mass index (BMI), as efficacy for various devices is reported by obesity class. Class I obesity includes BMI $30.0-34.9 \mathrm{~kg} / \mathrm{m}^{2}$, Class II includes BMI $35.0-39.9 \mathrm{~kg} / \mathrm{m}^{2}$, and Class III is BMI $>40.0 \mathrm{~kg} / \mathrm{m}^{2}$.

\section{Orbera}

The Apollo Orbera intragastric balloon (Apollo Endosurgery, Austin, TX, USA) is made from silicone elastomer and intended to be filled with $400-700 \mathrm{~mL}$ of saline (Figure 1A). ${ }^{7}$ Formerly called the BioEnterics Intragastric Balloon, the device was placed in over 220,000 patients outside the USA for nearly two decades before it was approved by the Food and Drug Administration in 2015.

Orbera is FDA approved for a 6-month placement in adults with BMI of $30-40 \mathrm{~kg} / \mathrm{m}^{2}$. An endoscopy should be

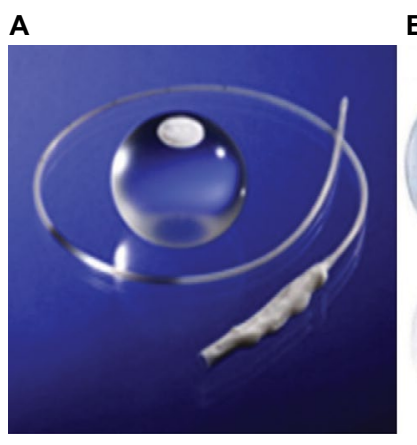

B

Figure I (A) Apollo Orbera intragastric balloon and (B) ReShape Integrated Dual Balloon system.

Note: Reprinted from Gastrointest Endosc, 8I (5), Abu Dayyeh BK, Edmundowicz SA, Jonnalagadda S, et al; ASGE Bariatric Endoscopy Task Force; ASGE Technology Committee, Endoscopic bariatric therapies, 1073-1086, Copyright (2015), with permission from Elsevier. ${ }^{7}$

performed before or concurrently with placement to rule out contraindications, such as large hiatal hernia or gastric ulcer. The endoscopy for placement can be performed using conscious sedation. The balloon is inserted on a catheter, and an endoscope can follow the catheter down the esophagus to ensure intragastric positioning before filling. The endoscopy for removal 6 months later can be performed with conscious sedation; however, deaths from aspiration pneumonia potentially associated with balloon removal have occurred. Moreover, balloon removal may be difficult, and therefore, many endoscopists perform balloon removal with endotracheal intubation and general anesthesia. In order to ease removal, the patient should be on a liquid diet for 2-3 days before and nil per os for at least 12 hours. The balloon is punctured and the saline is aspirated from the balloon using an endoscopic needle, and then a grasper is used to grasp and remove the deflated balloon.

\section{IDB system}

The ReShape IDB system (ReShape, San Clemente, CA, USA) is made from two silicone balloons attached to a silicone tube (Figure 1B). The ReShape IDB was FDA approved in 2015 for adults with BMI of $30-40 \mathrm{~kg} / \mathrm{m}^{2}$ with an obesity-related comorbidity. The ReShape IDB is inserted over a guide wire, and filled with a total of $750-900 \mathrm{~mL}$ of saline, depending on patient size. The balloon can be filled with a purpose-specific electric pump. The saline is dyed with methylene blue, which changes the color of the urine to green in the event of a balloon leak. The balloon is sealed with mineral oil. A purpose-specific catheter is used to aspirate saline from the balloon. A standard hexagonal snare can be used to grasp the proximal tip of the balloon for removal. Over 12,000 ReShape IDBs have been placed in clinical practice. 


\section{AspireAssist}

AspireAssist (Aspire Bariatrics, King of Prussia, PA, USA) allows for aspiration therapy, in which food is removed from the stomach after ingestion (Figure 2). It was approved by the FDA in 2016 for patients with BMI of $35-55 \mathrm{~kg} / \mathrm{m}^{2}$. The device includes a 30-French percutaneous endoscopic gastrostomy device (called an aspiration tube), an external port at the skin for aspiration, and a portable device that attaches to the port to perform flushing and aspiration. AspireAssist allows for consumption of a meal, infusion of water, and then aspiration of a portion of the meal. The aspiration tube is inserted endoscopically with a standard pull technique, and the external port is attached after 2 weeks.

\section{Comparative safety, efficacy, and tolerability Orbera}

The American Society for Gastrointestinal Endoscopy published a meta-analysis assessing the safety and efficacy of Orbera. ${ }^{8}$ The therapy achieved $11.3 \%$ total weight loss and $25.4 \%$ excess weight loss at 12 months post-balloon placement. Adverse events included abdominal pain (33.7\%), nausea (29\%), early explantation (7.5\%), migration (1.4\%), and gastrointestinal perforation $(0.1 \%)$. The meta-analysis results for efficacy and safety surpassed the Preservation and Incorporation of Valuable endoscopic Innovations targets set by the American Society for Gastrointestinal Endoscopy, which has established minimum standards for safety and effectiveness of EBT adopted into clinical practice.

Preservation of weight lost during Orbera therapy over subsequent years has been studied. In 500 patients with pre-Orbera average BMI of $43.7 \mathrm{~kg} / \mathrm{m}^{2}$, average BMI loss was $8.3 \mathrm{~kg} / \mathrm{m}^{2}$ with Orbera therapy. ${ }^{9}$ At 5 years (with $41 \%$ follow-up), average BMI loss was $2.5 \mathrm{~kg} / \mathrm{m}^{2}$. The percentage of patients achieving over $20 \%$ excess weight loss was $53 \%$ at 12 months (6 months after removal) and $23 \%$ at 5 years.
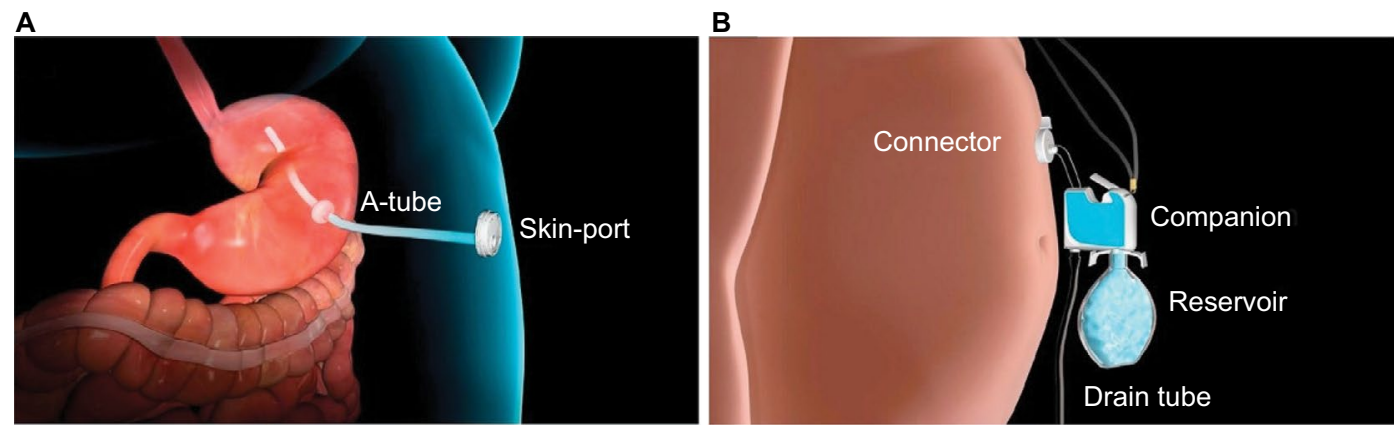

Figure 2 Aspire Bariatrics AspireAssist.

Notes: (A) Aspiration tube and skin port in place. (B) External device connected for aspiration. Reprinted from Gastroenterology, I45(6), Sullivan S, Stein R, Jonnalagadda S, Mullady D, Edmundowicz S, Aspiration therapy leads to weight loss in obese subjects: a pilot study, I245-1252, Copyright (2013), with permission from Elsevier. ${ }^{24}$ 
control group. Second Orbera resulted in BMI of 30.9 \pm 7.2 versus $35.9 \pm 9.7 \mathrm{~kg} / \mathrm{m}^{2}$ with dietary management.

Orbera can be effective as a bridge therapy to gastric bypass, in order to improve the patient's preparedness to undergo surgery. A trial of Orbera as bridge therapy included 60 subjects with average BMI of $66.5 \pm 3.4 \mathrm{~kg} / \mathrm{m}^{2}$, of whom 23 had Orbera therapy before surgery and 37 proceeded directly to surgery. ${ }^{15}$ Orbera resulted in average BMI decrease of $5.5 \pm 1.3 \mathrm{~kg} / \mathrm{m}^{2}$ prior to surgery and significant improvement in systolic blood pressure and liver enzymes. The Orbera group had shorter surgery duration (146 \pm 47 versus $201 \pm 81 \mathrm{~min}$ ). There was a significantly lower rate of major adverse events ( 2 versus 13) including conversion to laparotomy, intensive care longer than 2 days, and stay longer than 2 weeks in the Orbera group. Weight decrease at 1 year after gastric bypass was similar.

Patients with depression have demonstrated improvement with Orbera therapy. A study of 100 female subjects (65 with depression and 35 without depression) reported similar weight loss during Orbera therapy - excess weight loss of $39.3 \%$ in depressed subjects versus $36.1 \%$ in nondepressed subjects. ${ }^{16}$ Beck's Depression Inventory score decreased from $20.3 \pm 8.5$ to $7.9 \pm 5.6$ with Orbera therapy. Depression resolved in $70.8 \%$ of subjects with depression, and the rate of severe depression improved from $27.7 \%$ to $1.5 \%$.

Uncommon adverse events reported include pancreatitis, gastric volvulus, and dehydration with acute renal failure or severe electrolyte derangement due to post-placement nausea and vomiting. ${ }^{17-21}$

\section{IDB system}

The REDUCE trial was a randomized sham-controlled trial including 187 subjects undergoing ReShape IDB placement and 139 undergoing sham endoscopy; both groups were enrolled in a diet and lifestyle therapy program..$^{22}$ Excess weight loss was $25.1 \%$ after ReShape IDB (and $27.9 \%$ in the 167 completers) versus $11.3 \%$ after sham endoscopy. Additionally, waist size decreased 2.2 inches in the IDB group after 48 weeks. Obesity-related comorbidities improved at 6 months, including hypertension (systolic blood pressure fell by $8.3 \mathrm{mmHg}$ ), hemoglobin A1c (decrease of 0.2 points), and low-density lipoprotein (decrease of $4.1 \mathrm{mg} / \mathrm{dL}$ ). Nine percent of the devices were removed early due to intolerance. However, this was partly due to a single fill volume at the start of the trial. The early device intolerance was largely in patients with a height of 64 inches or less, and led to a reduction in fill volume to $375 \mathrm{~mL}$ in each balloon for patients with a height of $5^{\prime} 4^{\prime \prime}$ or shorter, which significantly decreased the rate of early device intolerance. No device migrations were reported. In the ReShape IDB arm, 21 subjects required emergency department visit for accommodative symptoms. Additional device-related adverse events included a contained perforation of the cervical esophagus during retrieval treated with intravenous antibiotics, a mucosal tear of the esophagus during retrieval treated with hemostatic clips, an ulcer at the gastroesophageal junction complicated by bleeding requiring blood transfusion, and pneumonitis after retrieval treated with antibiotics. Gastric ulcers were found in $35 \%$ of subjects, and redesign of the device tip resulted in $74 \%$ reduction in the ulcer rate.

An European private practice study of 60 patients with BMI of $38.8 \mathrm{~kg} / \mathrm{m}^{2}$ undergoing ReShape IDB placement reported BMI decrease of $6.1 \mathrm{~kg} / \mathrm{m}^{2}$, with mean total weight loss of $16.6 \mathrm{~kg}$ or $15.4 \%{ }^{23}$ Excess weight loss was $47.1 \%$. The balloon was well tolerated, with one early removal due to intolerance and one early deflation without migration. There was one gastric perforation. Small, clinically insignificant ulcers or erosions were noted in $23.3 \%$ of patients during endoscopy for balloon removal.

\section{AspireAssist}

A pilot randomized trial of AspireAssist in the USA compared 11 subjects undergoing AspireAssist with seven controls; all underwent diet and lifestyle counseling. ${ }^{24} \mathrm{Of}$ these, 10 AspireAssist subjects with BMI of $42.0 \pm 1.4 \mathrm{~kg} / \mathrm{m}^{2}$ and four controls with BMI of $39.3 \pm 1.1 \mathrm{~kg} / \mathrm{m}^{2}$ completed the study. At 1 year, the AspireAssist subjects lost 18.6\% $\pm 2.3 \%$ of total weight, whereas the controls lost $5.9 \% \pm 5.0 \%$. Of the AspireAssist subjects, seven continued the study for another year and reached $20.1 \% \pm 3.5 \%$ total weight loss. Notably, using the AspireAssist was not associated with the development of eating disorders. The adverse events included three infections and one fistula (which spontaneously closed) at the tube site after it was removed.

The randomized, multicenter PATHWAY trial included 111 subjects undergoing AspireAssist with lifestyle counseling and 60 subjects undergoing lifestyle counseling only. ${ }^{25}$ Average BMI was similar between the groups $(42.0 \pm 5.1$ $\mathrm{kg} / \mathrm{m}^{2}$ for AspireAssist and $40.9 \pm 3.9 \mathrm{~kg} / \mathrm{m}^{2}$ for lifestyle counseling). At 1 year, AspireAssist resulted in significantly greater weight loss in those subjects who completed the trial (37.2\% $\pm 27.5 \%$ excess weight loss with AspireAssist versus $13.0 \% \pm 17.6 \%$ with lifestyle counseling only). Adverse events included abdominal pain after aspiration tube placement, peristomal granulation tissue, and peristomal irritation. Eating behavior and psychological evaluation during follow-up demonstrated no evidence of abnormal eating behaviors, 
development of eating disorders, or increased intake to compensate for aspirated calories.

The weight loss seen with AspireAssist in the US pilot study was consistent with a single-arm study performed in Europe. In this trial, 25 subjects (BMI $39.8 \pm 0.9 \mathrm{~kg} / \mathrm{m}^{2}$ ) completed very low-calorie diet (800 kilocalories per day or less) for 1 month, followed by AspireAssist. ${ }^{26}$ After 6 months, 22 subjects who completed treatment demonstrated weight loss of $16.5 \pm 7.8 \mathrm{~kg}(8.0 \pm 7.4 \mathrm{~kg}$ excluding VLCD). This was equivalent to $14.8 \% \pm 6.3 \%$ total weight loss and $40.8 \% \pm 19.8 \%$ excess weight loss. Type 2 diabetics had significant improvement in blood glucose, and $3 / 5$ were able to discontinue diabetic medications. After the procedure, the adverse events included abdominal pain (moderate in $52 \%$ and severe in $12 \%$ ), intra-abdominal fluid collection, and peristomal skin breakdown. Later, a skin infection was treated with antibiotics. This demonstrates the consistency of this therapy across different cultures.

\section{Therapy selection}

EBTs have established a position in the continuum of multidisciplinary therapy for obesity. Intragastric balloons have a long track record of safety and efficacy and have attained commercial acceptance around the world. In international use, the Orbera has been studied as a bridge to bariatric or other surgery, placed twice sequentially, and used in patients with BMI exceeding $50 \mathrm{~kg} / \mathrm{m}^{2}$. In the USA, intragastric balloons are indicated for patients with Class I and II obesity, and for removal 6 months after placement. The IDB system has demonstrated comparable safety and efficacy, although the small risk of migration associated with Orbera is reduced with the dual balloon due to the presence of two balloons. The long-term durability of weight loss after intragastric balloon is dependent upon patient factors and the efficacy of the supporting weight loss program, including the ability to continue maintenance of dietary habits established during treatment. Additional therapies, such as weight loss medications, are available to maintain weight loss if needed. Aspiration therapy has been approved for a broader BMI range $\left(35-55 \mathrm{~kg} / \mathrm{m}^{2}\right)$ than intragastric balloons. It has also been studied for long durations, exceeding 2 years. Aspiration therapy does offer a greater magnitude of weight loss than typically seen with intragastric balloon therapy. Like intragastric balloon therapy, aspiration therapy warrants ongoing dietary and lifestyle counseling, and long-term success depends upon the durability of patient behavior. Ultimately, unless the decision is dictated by patient BMI, patients have the opportunity to choose between multiple safe and effective EBT, and more are forthcoming.

\section{Conclusion}

Obesity has grown in scale and impact around the world over the past few decades. Noninvasive options, such as diet and lifestyle modification, have had minimal efficacy at the population level. Invasive options, primarily bariatric surgery, have been scarcely utilized at the population level. With the recent approval of new pharmacotherapy, intragastric balloons, and aspiration therapy, patients have a more complete range of treatment options. The intragastric balloons offer nonsurgical, reversible weight management that has proven to be more effective than diet and lifestyle therapy. Aspiration therapy addresses a broader BMI range and offers the potential for a significant and durable weight loss. As more EBT for obesity become available and multidisciplinary programs are developed to offer long-term follow-up, the treatment of obesity will continue to evolve.

\section{Disclosure}

Nitin Kumar, consultant in safety for Obalon. Shelby Sullivan, contracted research for ReShape Medical, GI Dynamics, Aspire Bariatrics, USGI Medical, Obalon Therapeutics, BAROnova. Paion, consultant for USGI Medical, Obalon, Elira Therapeutics, SynerZ, Spatz FGIA, and Aspire Bariatrics. Christopher C Thompson: Boston Scientific - consultant (consulting fees), Covidien - consultant (consulting fees)/ endoluminal advisory board member, USGI Medical - consultant (consulting fees)/advisory board member (consulting fees)/research support (research grant), Valentx - consultant (consulting fees), Olympus - lab support (lab supplies/ equipment), consultant, Apollo Endosurgery - consultant/ research support (consulting fees/research grants), GI Windows - ownership interest, Aspire Bariatrics - research grant, Fractyl - consultant/advisory board member, GI Dynamics - expert reviewer, Spatz - research grant. The authors report no other conflicts of interest in this work.

\section{References}

1. Allison DB, Downey M, Atkinson RL, et al. Obesity as a disease: a white paper on evidence and arguments commissioned by the council of the obesity society. Obesity (Silver Spring). 2008;16(6): 1161-1177.

2. AMA. Report of the Council on Science and Public Health. Chicago, IL: AMA; 2013. Available from: http://www.ama-assn.org/assets/ meeting/2013a/a13-addendum-refcomm-d.pdf\#page=19. Accessed December 14, 2016.

3. Ward ZJ, Long MW, Resch SC, et al. Redrawing the US obesity landscape: bias-corrected estimates of state-specific adult obesity prevalence. PLoS One. 2016;11(3):e0150735.

4. Turk MW, Yang K, Hravnak M, Sereika SM, Ewing LJ, Burke LE Randomized clinical trials of weight-loss maintenance: a review. J Cardiovasc Nurs. 2009;24(1):58-80.

5. Nguyen NT, Vu S, Kim E, Bodunova N, Phelan MJ. Trends in utilization of bariatric surgery, 2009-2012. Surg Endosc. 2016; 30(7) 2723-2727. 
6. Sullivan S, Kumar N, Edmundowicz SA, et al; ASGE Bariatric Endoscopy Task Force. ASGE position statement on endoscopic bariatric therapies in clinical practice. Gastrointest Endosc. 2015;82(5):767-772.

7. Abu Dayyeh BK, Edmundowicz SA, Jonnalagadda S, et al; ASGE Bariatric Endoscopy Task Force; ASGE Technology Committee. Endoscopic bariatric therapies. Gastrointest Endosc. 2015;81(5):1073-1086.

8. Abu Dayyeh BK, Kumar N, Edmundowicz SA, et al; ASGE Bariatric Endoscopy Task Force; ASGE Technology Committee. ASGE bariatric endoscopy task force systematic review and meta-analysis assessing the ASGE PIVI thresholds for adopting endoscopic bariatric therapies. Gastrointest Endosc. 2015;82(3):425-438.

9. Kotzampassi K, Grosomanidis V, Papakostas P, Penna S, Eleftheriadis E. 500 intragastric balloons: what happens 5 years thereafter? Obes Surg. 2012;22(6):896-903.

10. Mitura K, Garnysz K. Tolerance of intragastric balloon and patient's satisfaction in obesity treatment. Wideochir Inne Tech Maloinwazyjne. 2015;10(3):445-449.

11. Genco A, López-Nava G, Wahlen C, et al. Multi-centre European experience with intragastric balloon in overweight populations: 13 years of experience. Obes Surg. 2013;23(4):515-521.

12. Dumonceau JM, François E, Hittelet A, Mehdi AI, Barea M, Deviere J. Single vs repeated treatment with the intragastric balloon: a 5-year weight loss study. Obes Surg. 2010;20(6):692-697.

13. Lopez-Nava G, Rubio MA, Prados S, et al. BioEnterics ${ }^{\circledR}$ intragastric balloon $(B I B \circledR)$. Single ambulatory center Spanish experience with 714 consecutive patients treated with one or two consecutive balloons. Obes Surg. 2011;21(1):5-9.

14. Genco A, Cipriano M, Bacci V, et al. Intragastric balloon followed by diet vs intragastric balloon followed by another balloon: a prospective study on 100 patients. Obes Surg. 2010;20(11):1496-1500.

15. Zerrweck C, Maunoury V, Caiazzo R, et al. Preoperative weight loss with intragastric balloon decreases the risk of significant adverse outcomes of laparoscopic gastric bypass in super-super obese patients. Obes Surg. 2012;22(5):777-782.
16. Deliopoulou K, Konsta A, Penna S, Papakostas P, Kotzampassi K. The impact of weight loss on depression status in obese individuals subjected to intragastric balloon treatment. Obes Surg. 2013;23(5):669-675.

17. Said F, Robert S, Mansour el K. Pancreatitis and intragastric balloon insertion. Surg Obes Relat Dis. 2016;12(3):e33-e34.

18. Navajas-Laboa M, Bridet L, Orive-Calzada A, Cabriada-Nuno JL. Intragastric balloon and epigastric pain: beware of the pancreas. Turk $J$ Gastroenterol. 2015;26(1):87-88.

19. Mercky P, Ah-Soune P, Bernardini D. A surprising complication of an intragastric balloon: a gastric volvulus. Endoscopy. 2014;46(Suppl 1): E403.

20. Palacios-García L, Gutiérrez-Macías A, García-González P, LartategiIraurgi A. Life-threatening hyponatremia, hypokalemia, and metabolic alkalosis after intragastric balloon placement. Gastrointest Endosc. 2016;83(4):855-856.

21. Milone M, Maietta P, Bianco P, et al. An early onset of acute renal failure in a young woman with obesity and infertility who underwent gastric balloon positioning. A case report. G Chir. 2014;35(3-4):73-74.

22. Ponce J, Woodman G, Swain J, et al; REDUCE Pivotal Trial Investigators. The REDUCE pivotal trial: a prospective, randomized controlled pivotal trial of a dual intragastric balloon for the treatment of obesity. Surg Obes Relat Dis. 2015;11(4):874-881.

23. Lopez-Nava G, Bautista-Castaño I, Jimenez-Baños A, FernandezCorbelle JP. Dual intragastric balloon: single ambulatory center Spanish experience with 60 patients in endoscopic weight loss management. Obes Surg. 2015;25(12):2263-2267.

24. Sullivan S, Stein R, Jonnalagadda S, Mullady D, Edmundowicz S. Aspiration therapy leads to weight loss in obese subjects: a pilot study. Gastroenterology. 2013;145(6):1245-1252.e1-e5.

25. Thompson CC, Abu Dayyeh BK, Kushner K, et al. The AspireAssist is an effective tool in the treatment of class II and class III obesity: results of a one-year clinical trial. Gastroenterology. 2016;4(Suppl 1):S86.

26. Forssell H, Norén E. A novel endoscopic weight loss therapy using gastric aspiration: results after 6 months. Endoscopy. 2015;47(1):68-71.
Diabetes, Metabolic Syndrome and Obesity: Targets and Therapy is an international, peer-reviewed open-access journal committed to the rapid publication of the latest laboratory and clinical findings in the fields of diabetes, metabolic syndrome and obesity research. Original research, review, case reports, hypothesis formation, expert opinion and commentaries are all considered for publication. The manuscript management system is completely online and includes a very quick and fair peer-review system, which is all easy to use. Visit http://www.dovepress.com/testimonials.php to read real quotes from published authors. 